\title{
THE IMPACT OF REMANUFACTURING IN THE ECONOMY
}

\author{
by \\ G. FERRER* \\ and \\ R.U. AYRES** \\ 98/14/EPS \\ (Revised Version of 97/52/TM)
}

This Working Paper was published in the context of INSEAD's Centre for the Management of Environmental Resources, an R\&D partnership sponsored by Ciba-Geigy, Danfoss, Otto Group and Royal Dutch/Shell and Sandoz AG.

* Assistant Professor, The Kenan-Flagler Business School, The University of North Carolina at Chapel Hill.

** Sandoz Professor of Management and the Environment at INSEAD, Boulevard de Constance, 77305 Fontainebleau Cedex, France.

A working paper in the INSEAD Working Paper Series is intended as a means whereby a faculty researcher's thoughts and findings may be communicated to interested readers. The paper should be considered preliminary in nature and may require revision.

Printed at INSEAD, Fontainebleau, France. 


\title{
The Impact of Remanufacturing in the Economy
}

\author{
Geraldo Ferrer ${ }^{1}$ and Robert U. Ayres ${ }^{2}$
}

\begin{abstract}
Very few durable goods are recovered at the end of their useful lives. However, this situation could reverse with the development of a stronger remanufacturing industry in the economy. This paper evaluates the impact of remanufacturing in a hypothetical situation where remanufacturing holds a significant share of the economy, presently dominated by the original manufacturing industries. It would have direct impacts on the demand for several inputs. We adapt the inter-industry input-output framework with the development of a methodology to consider these changes. Subsequently, we apply the model to the 30-sector aggregation of the French input-output national data to illustrate the nethod and to evaluate the impact that remanufacturing may have on the economy. The analysis assumes that remanufacturing sectors substitute labor and transport services for the usual inputs such as raw materials and semi-finished goods. We find that remanufacturing may satisfy the same final demand from all sectors requiring fewer intermediate resources, with proportionally higher demand of labor.
\end{abstract}

Keywords: remanufacturing, product recovery, inter-industry flows, input-output model, France

\section{Introduction}

The production of durable goods represents an important contribution to the GNP of all developed countries. It employs large amounts of human resources, raw materials and energy. However, most of the resources consumed are not renewable. The minerals that provide most of the raw materials and energy in the production of durable goods have been continually depleted. Moreover, many durable products are disposed in landfills at the end of their useful lives, without undergoing any recovery process. The landfill space has been decreasing and the prices charged by the landfills still in operation have increased very fast. ${ }^{3}$

Ayres, Ferrer and Van Leynseele (1997) suggested that remanufacturing is one approach to deal with the used durable goods at the time of disposal, because of two first-order effects. In the production side, remanufacturing reduces the demand for raw materials since part of the production is assured by the recovery of used goods: it is the resource conservation effect. In the disposal side, remanufacturing provides an alternative stream for used durable goods at the end

\footnotetext{
${ }^{1}$ Assistant Professor, The Kenan-Flagler Business School, The University of North Carolina at Chapel Hill, Chapel Hill, NC 27599-3490. E-mail: geraldo_ferrer@unc.edu.

${ }^{2}$ Sandoz Professor of Environment and Management, INSEAD, Blvd. Constance, F-77305 Fontainebleau, France. E-mail: ayres@insead.fr

${ }^{3}$ The authors would like to thank Landis Gabel, Faye Duchin and two anonymous referees for their valuable comments that allowed significant improvements of this paper.
} 
of their useful lives. It reduces the amount of landfilled material given that significant fractions of the durable goods are reused: it is the waste reduction effect.

Today, there are two major constraints precluding the expansion of remanufacturing activities. The existing infrastructure is not suitable for the return flow, and most products arriving at the end of the first useful life are not designed for remanufacturing. This situation may change. Manufacturers are more conscious of their responsibility regarding product disposal, and are considering the adoption of Design for the Environment (DFE). In addition, changes in legislation may require manufacturers (or importers) to take back the carcasses of end-of-life automobiles, electronic goods and other durable products for responsible disposal or, preferably, recovery. Consequently, when the industry adopts efficient reverse logistics and design for the environment, one may see a substantial increase in the remanufacturing activity, even if regulation fails to require it. Since remanufacturing affects the level of consumption of several inputs (raw materials, labor and energy), it will have significant impact on the economy, as it becomes a generalized practice.

The remanufacturing success stories available today (photocopiers, disposable cameras) represent a tiny fraction of economic activity. Thus, we cannot be certain about their secondorder effects. For example, intuition says that the reduction in the consumption of raw materials reduces the demand from utility suppliers and machinery manufacturers. Likewise, employment is reduced in the same industries. Nevertheless, it is hard to guess what direction total employment will take, since remanufacturing is also a labor-intensive activity. Original manufacturing (usually mass production) is much more able to capture economies of scale than remanufacturing. Due to heterogeneous inputs, the typical production rule adopts small lots. Also, disassembly is inherently more labor intensive, and less amenable to automation than is assembly. These questions have to be dealt carefully, in order to understand if remanufacturing is an activity to be supported by governmental action or not.

In this paper, we develop a model for evaluating the economic impact of a generalized product recovery and remanufacturing activity. The matrix of inter-industry transactions is augmented, to incorporate the remanufacturing sector. It is adapted to recognize the different demands in labor, energy, raw materials, and inputs from the other industries. A basic assumption is that the final demand (in physical units) from remanufacturing and from original manufacturing remains the same as in the original scenario. In addition, it is assumed that the remanufactured product is sold at a price lower than that of a new good. Consequently, because of the unit price reduction, the monetary demand (total sales) is reduced. This drives the firstorder effect of implementing remanufacturing. However, the higher-order effects are harder to estimate, but the methodology in this paper allows the identification of their impact.

Key questions are: what would it happen if durable goods, such as automobiles, trucks, televisions and personal computers, were substantially remanufactured? How would it affect the 
demand for the traditional inputs in these industries? How would the massive presence of remanufactured goods affect the demand for raw materials? Some of the inputs, like energy and semi-finished goods, are expected to decline but labor utilization might increase. The main contribution of this paper is to generate the methodology that enables answering these questions. In order to decide on the implementation of take-back regulations, policy makers and industrial lobbies need to understand the consequences of such decisions in the whole economy.

\section{The input-output methodology}

Leontief (1936) first developed the input-output model as an analytical framework describing the interdependence of different industrial sectors. The model requires the preparation of an economy-wide table, generally compiled by the statistical agency of the national government. Each entry in the table corresponds to the sales from a given industrial sector to another industrial sector. One fundamental assumption in the framework is that the production function of all industries is linear. That is, if the total output of a given sector is increased, its consumption from (or payments to) all other sectors is increased in the same proportion ${ }^{4}$. This implies that the technical coefficients are the fixed set of parameters under which the economy operates. Another assumption is that the technical coefficients do not change unless there is some change in the technology employed in one or more sectors ${ }^{5}$.

The input-output model has been extensively used to evaluate the impact of structural changes in the economy. Some have used this model to evaluate the changes due the increased consumption of a given commodity, as in Chen and Vella (1994), Davis (1987) and Howell (1985). Others have used it to evaluate the implication of environmental control policies, such as Hannan and Rose (1988), Lee (1982), Lowe (1979) and Rhee and Miranowski (1984). Finally, some have evaluated the dynamic changes in a given economy using the input-output tables of successive years, as in Common and McPherson (1982), Driver (1994), Feldman, McClain and Palmer (1987) and Lauritzen (1982). In what follows, we show the basic mathematics used in this type of evaluation.

Consider an input-output table as just described. Let $\mathbf{Z}$ be the $\mathrm{n} \times \mathrm{n}$ matrix of interindustry transactions, $\mathbf{Y}$ the column vector of final demands and $\mathbf{X}$ the column vector of total outputs. For any sector i, by construction,

$$
X_{i}=Z_{i 1}+Z_{i 2}+\ldots+Z_{\text {in }}+Y_{i}
$$

\footnotetext{
${ }^{4}$ The linearity in the input-output model is in great contrast with the Cobb-Douglas production function, as discussed by Burress (1994).

${ }^{5}$ In practice, technological changes do occur in most sectors every period. One should expect to find different matrices of technical coefficients each year, reflecting these changes.
} 
This expression corresponds to the sum of all sales made by sector $i$ in the economy. Each $Z_{\mathrm{ij}}$ element in the right-hand side corresponds to the inter-industry sales from sector $i$ to sector $j$. Let $A_{i j}$ be the ratio between each element $Z_{i j}$ and the total output of the sector, $X_{j}$. That is

$$
A_{i j}=Z_{i j} / X_{j}
$$

This generates the matrix of technical coefficients, $\mathbf{A}$. Eliminating $\mathbf{Z}$ from both sets of equations, we obtain the expression

$$
\text { (I-A) } \mathbf{X}=\mathbf{Y}
$$

In general, the matrix (I-A) is nonsingular, that is, its determinant is not zero ${ }^{6}$. Hence:

$$
\mathbf{X}=(\mathbf{I}-\mathbf{A})^{-1} \mathbf{Y}
$$

Until recently, the main practical difficulty dealing with input-output tables was to produce this matrix, given the complexity of performing large matrix operations. One simple way to overcome this problem is to use the expansion

$$
(\mathbf{I}-\mathbf{A})^{-1}=\mathbf{I}+\mathbf{A}+\mathbf{A}^{2}+\ldots
$$

Currently, typical spreadsheet programs can invert matrices of up to 50 dimensions very quickly. A specialized FORTRAN code might invert much larger matrices using minimal resources. In this paper, we limit the size of the problem using a 30-sector aggregation of the French national economy in 1991

The remaining difficulty using input-output tables is to adapt the tables generally made available by official sources into one that contains the sectors that we want to analyze. This adaptation requires two sets of operations: sector aggregation and sector disaggregation.

\subsection{Disaggregating input-output tables}

Suppose one wishes to evaluate the impact of substituting one type of raw material for another. The study will be constrained by the level of aggregation of the data of the respective industries. Sometimes, the industries studied might be conveniently isolated in the tables. But it is usually not the case. For example, if the data from all firms producing nonferrous metals are aggregated in a single nonferrous sector, one cannot evaluate the effect of substituting copper cables for aluminum cables using the tables as they were originally prepared. A number of researchers have worked on the problem of disaggregating input-output tables. The work by Wolsky (1984) deals precisely with it.

\footnotetext{
${ }^{6}$ Often, the matrix $(\mathbf{I}-\mathbf{A})$ is called the Leontief matrix, and its inverse is called the Leontief inverse matrix.
} 
Let $\mathbf{A}$ and $\mathbf{B}$ be the two technical coefficient matrices of the same economy, where $\mathbf{A}$ is the $n \times n$ matrix obtained from the aggregation of matrix $B, a(n+1) \times(n+1)$ matrix. For simplicity of exposition, the first $n-1$ sectors in both matrices are the same. The $n$th sector in matrix $\mathbf{A}$ is the aggregation of the last two sectors in matrix $\mathbf{B}$. Hence, each element in matrix $\mathbf{A}$ relates to the elements in $\mathbf{B}$ as follows:

$$
\mathbf{A}=\left[\begin{array}{cccc}
A_{11} & \cdots & & A_{1 n} \\
A_{21} & & & A_{2 n} \\
\vdots & & & \vdots \\
A_{n 1} & A_{n 2} & \cdots & A_{n n}
\end{array}\right]=\left[\begin{array}{ccccc}
1 & 0 & \cdots & 0 & 0 \\
0 & 1 & & 0 & 0 \\
\vdots & & \ddots & \vdots & \vdots \\
0 & 0 & \cdots & 1 & 1
\end{array}\right]\left[\begin{array}{ccccc}
B_{11} & B_{12} & \cdots & & B_{1, n+1} \\
B_{21} & B_{22} & & & \\
\vdots & & \ddots & & \vdots \\
B_{n 1} & & & B_{n n} & \\
B_{n+1,1} & \cdots & & & B_{n+1, n+1}
\end{array}\right]\left[\begin{array}{cccc}
1 & 0 & \cdots & 0 \\
0 & 1 & & 0 \\
\vdots & & \ddots & \vdots \\
0 & 0 & \cdots & p \\
0 & 0 & \cdots & q
\end{array}\right]
$$

where $p$ (or $q$, respectively) is the ratio of the total output from sector $n$ (or sector $n+1$ ) to the sum of the total output of sectors $n$ and $(n+1)$. This operation allows defining the aggregated matrix A from a larger matrix B. One may use this set of equations to aggregate related sectors that are not directly involved in the analysis. (For example, in this paper, in order to facilitate the evaluation of the remanufacturing effects in the economy, we aggregate some sectors that are not strongly related with the manufacture or utilization of durable goods.)

However, if one wishes to obtain the disaggregated matrix $\mathbf{B}$ from the smaller matrix $\mathbf{A}$, one will find that the system is underspecified. For a given $\mathrm{n} \times \mathrm{n}$ matrix, there will be several $(n+1) \times(n+1)$ matrices satisfying this set of equations. Wolsky approached this problem by introducing the augmented matrix and distinguishing matrix. The disaggregated matrix (B) is the sum of the augmented $(\mathbf{H})$ and the distinguishing $(\mathbf{D})$ matrices.

The augmented matrix $\mathbf{H}$ is one of the many $(n+1) x(n+1)$ matrices satisfying the set of equations above. It is defined as the one matrix where sectors $n$ and $n+1$ require the same inputs, controlling market shares of $\mathrm{p}$ and $\mathrm{q}$, respectively.

$$
\mathbf{H}=\left[\begin{array}{ccccc}
\mathrm{H}_{11} & \mathrm{H}_{12} & \cdots & & \mathrm{H}_{1, \mathrm{n}+1} \\
\mathrm{H}_{21} & \mathrm{H}_{22} & & & \\
\vdots & & \ddots & & \vdots \\
\mathrm{H}_{\mathrm{n} 1} & & & \mathrm{H}_{\mathrm{nn}} & \\
\mathrm{H}_{\mathrm{n}+1,1} & \cdots & & & \mathrm{H}_{\mathrm{n}+1, \mathrm{n}+1}
\end{array}\right]=\left[\begin{array}{cccc}
1 & 0 & \cdots & 0 \\
0 & 1 & & 0 \\
\vdots & & \ddots & \vdots \\
0 & 0 & \cdots & \mathbf{p} \\
0 & 0 & \cdots & \mathrm{q}
\end{array}\right]\left[\begin{array}{cccc}
\mathrm{A}_{11} & \cdots & & \mathrm{A}_{1 \mathrm{n}} \\
\mathrm{A}_{21} & & & \mathrm{~A}_{2 \mathrm{n}} \\
\vdots & & & \vdots \\
\mathrm{A}_{\mathrm{n} 1} & \mathrm{~A}_{\mathrm{n} 2} & \cdots & \mathrm{A}_{\mathrm{nn}}
\end{array}\right]\left[\begin{array}{ccccc}
1 & 0 & \cdots & 0 & 0 \\
0 & 1 & & 0 & 0 \\
\vdots & & \ddots & \vdots & \vdots \\
0 & 0 & \cdots & 1 & 1
\end{array}\right]
$$

The auxiliary matrices pre- and post-multiplying matrix $\mathbf{A}$ are the same appearing in Eq. (1), operating in the opposite order. The operation can be easily generalized to situations when one wishes to perform multiple disaggregations. The augmented matrix considers sectors $\mathrm{n}$ and $n+1$ as essentially the same. The disaggregated matrix, however, must reflect the different inputs and outputs of these sectors. This distinction is obtained with the distinguishing matrix. Once we perform the matrix operations in (1) and (2), we must identify the parameters that characterize the distinguishing matrix $D$. Let $i<n$ and $j<n$ designate any of the $(n-1) \times(n-1)$ 
elements in matrix $\mathbf{A}$ that is identical to the corresponding elements in the larger matrix $\mathbf{B}$. Since, $\mathbf{D}=\mathbf{B}-\mathbf{H}$, we obtain

$$
\begin{aligned}
& B_{i j}=H_{i j}=A_{i j} \\
& \quad \Rightarrow D_{i j}=0, \forall i<n, j<n
\end{aligned}
$$

The $\mathrm{n}^{\text {th }}$ and the $(\mathrm{n}+1)^{\text {th }}$ rows in the $\mathbf{H}$ matrix assume that the market share across all columns is the same. This condition must be relaxed with the corresponding rows in the $\mathbf{D}$ matrix.

$$
\left\{\begin{array}{l}
B_{n j}+B_{n+1, j}=A_{n j} \\
p_{n j}=H_{n j} \\
q A_{n j}=H_{n+1, j}
\end{array}\right.
$$

$$
\Rightarrow D_{n j}=-D_{n+1, j}
$$

Also, the $\mathrm{n}^{\text {th }}$ and the $(n+1)^{\text {th }}$ columns in $\mathbf{H}$ are identical, assuming that both sectors use the same technology. The corresponding column in matrix $\mathbf{D}$ relaxes this condition.

$$
\begin{aligned}
& \left\{\begin{array}{l}
p B_{i n}+q B_{i, n+1}=A_{\text {in }} \\
H_{\text {in }}=H_{i, n+1}=A_{\text {in }}
\end{array}\right. \\
& \Rightarrow\left\{\begin{array}{l}
D_{\text {in }}=q\left(B_{i n}-B_{i, n+1}\right) \\
D_{i, n+1}=p\left(B_{i, n+1}-B_{i, n}\right)
\end{array}\right.
\end{aligned}
$$

Finally, the four elements in the lower-right corner of $\mathbf{H}$ incorporate both conditions mentioned above. The corresponding elements in $\mathbf{D}$ relaxes them as follows.

$$
\begin{aligned}
& \left\{\begin{array}{l}
p\left(B_{n n}+B_{n+1, n}\right)+q\left(B_{n, n+1}+B_{n+1, n+1}\right)=A_{n n} \\
H_{n n}=H_{n, n+1}=p A_{i n} \\
H_{n+1, n}=H_{n+1, n+1}=q A_{n n}
\end{array}\right. \\
& \Rightarrow\left\{\begin{array}{l}
D_{n n}+D_{n+1, n}=q\left(B_{n n}-B_{n, n+1}\right)+q\left(B_{n+1, n}-B_{n+1, n+1}\right) \\
D_{n, n+1}+D_{n+1, n+1}=p\left(B_{n, n+1}-B_{n n}\right)+p\left(B_{n+1, n+1}-B_{n+1, n}\right) \\
D_{n, n+1}+D_{n+1, n}=-\left(D_{n n}+D_{n+1, n+1}\right)
\end{array}\right.
\end{aligned}
$$

Notice that, since each $\mathrm{H}_{\text {in }}=\mathrm{H}_{\mathrm{i}, \mathrm{n}+1}$, than $\mathrm{B}_{\mathrm{in}}-\mathrm{B}_{\mathrm{i}, \mathrm{n}+1}=\mathrm{D}_{\mathrm{in}}-\mathrm{D}_{\mathrm{i}, \mathrm{n}+1}$. Hence, the distinguishing matrix $\mathbf{D}$ is completely defined with $n-1$ parameters to differentiate the last two rows, $n-1$ 
parameters to differentiate the last two columns, and 3 parameters to differentiate the four elements in the lower-right corner.

The row-differentiating parameters, call them $s_{j}$, indicate how much sector $\mathrm{j}$ departs from the average in its demand from sector $n$. They satisfy Eq. (4). The column-differentiating parameters, call them $d_{i}$, reflect the difference between sectors $n$ and $n+1$ in their demand for inputs from sector $i$. They satisfy Eq. (5). The last three parameters, $s_{n}, d_{n}$, and e satisfy Eq. (6). They serve the functions of row- and column-differentiating parameters with one additional degree of freedom given by $\mathrm{e}$, allowing full distinction between the sectors. Hence, the distinguishing matrix becomes:

$$
\mathbf{D}_{\mathbf{W}}=\left[\begin{array}{ccccc}
0 & 0 & \cdots & \mathrm{qd}_{1} & -\mathrm{pd}_{1} \\
0 & 0 & & \mathrm{qd}_{2} & -\mathrm{pd}_{2} \\
\vdots & & \ddots & & \vdots \\
\mathrm{s}_{1} & \mathrm{~s}_{2} & & \mathrm{~s}_{\mathrm{n}}+\mathrm{q}\left(\mathrm{d}_{\mathrm{n}}+\mathrm{e}\right) & \mathrm{s}_{\mathrm{n}}-\mathrm{p}\left(\mathrm{d}_{\mathrm{n}}+\mathrm{e}\right) \\
-\mathrm{s}_{1} & -\mathrm{s}_{2} & \cdots & -\mathrm{s}_{\mathrm{n}}+\mathrm{q}\left(\mathrm{d}_{\mathrm{n}}-\mathrm{e}\right) & -\mathrm{s}_{\mathrm{n}}-\mathrm{p}\left(\mathrm{d}_{\mathrm{n}}-\mathrm{e}\right)
\end{array}\right]
$$

The development of the distinguishing matrix, due to Wolsky, allows for the disaggregation of two sectors previously aggregated in the input-output tables. ${ }^{7}$ For example, to evaluate the effect of substituting copper cables for aluminum cables, one could use Wolsky's methodology to disaggregate the nonferrous metals sector into three sectors (aluminum, copper and other nonferrous metals). ${ }^{8}$ We use this methodology as a first-step to introduce the remanufacturing corresponding to a original manufacturing industry in the input-output matrix.

\section{Comparing remanufacturing and manufacturing activities}

Remanufacturing is the process where a used durable good is disassembled at the module or at the component level, to repair or substitute components and modules that are worn out or obsolete. In addition, the whole equipment is refurbished and critical modules are overhauled or substituted. A machine of today is built on yesterday's base, receiving all the enhancements, expected life and warranty of a new machine. One interesting advantage that often occurs with remanufactured goods is that several bugs that eventually existed in the original design are eliminated. Components in a remanufactured product tend to have much lower infant mortality than in an originally manufactured product. On the other hand, it is clear that components subjected to stress will have accumulated some fatigue - microscopic fractures that gradually compromise its performance. However, the reduction in the expected life of non-critical

\footnotetext{
${ }^{7}$ Wolsky (1984) also provided useful bounds for the parameters in the distinguishing matrix. Given the nature of our problem, they are not needed here.

${ }^{8}$ In reality, this disaggregation would be one of many required steps in a far more complex analysis.
} 
components often does not affect the expected life of the whole. It is the slack in expected life of valuable components that makes remanufacturing technically viable.

Remanufacturing has many similarities with the original manufacturing process. It also has some important differences. For the purpose of this study, we are interested in the difference between the inputs and the outputs of corresponding industries. For example, what is the difference between the inputs of tire manufacturing plants and tire retreading plants? What sectors absorb the output of one industry or another? The answer to this type of question is in the distinguishing matrix, specific for the input-output analysis when a new sector is introduced. The characteristics of the distinguishing matrix change significantly in our problem. Wolsky developed a method for disaggregating two industries operating independently in the same sector. Here, we would like to adapt it to analyze the introduction of the remanufacturing sector competing against an existing manufacturing industry, absorbing part of the market currently served by the original sector. Table 1 lists the steps necessary to initiate the analysis.

\section{INSERT Table 1 ABOUT HERE}

As the table indicates, a complete analysis starts with the estimation of the physical market share of the original sector (p), and the relative price exercised in the remanufacturing sector $(\delta<1)$. Initially, we consider that the final demand for the product (in physical units) is not changed and that the remanufactured product is sold at a lower price. Let $Y_{n}$ be the final demand from the original sector, in monetary units, before the introduction of remanufacturing. By construction, the new final demand from the original manufacturing sector becomes $p^{*} Y_{n}$.

Define $\delta$ as the ratio between the average prices of remanufactured and originally manufactured product. If the demand from the remanufacturing sector is $q^{*} Y_{n}$, it follows that $q=\delta^{*}(1-p) .^{9}$ Notice that reduced price in the new sector and constant physical output imply that $\mathrm{p}+\mathrm{q}<1$. Consequently, the sum of final demands from both sectors is reduced.

Example: the widget sector has a final demand of 100 units sold at $\$ 1$,. If a remanufactured widget sector develops, with a final demand of 40 units, the demand for virgin widgets becomes 60 units $(p=0.6)$, sold at $\$ 60$. Moreover, if the remanufactured widget is sold at $\$ 0.70(\delta=0.7)$ the sector's final demand is $\$ 28(q=0.28)$.

Steps 3 and 4 are straightforward. In the previous section, we explained how to obtain the disaggregated matrix by adding the distinguishing matrix to the augmented matrix. When it comes to the introduction of remanufacturing sectors, the augmented matrix is obtained similarly, but with a caveat. In addition to augmenting the matrix of inter-industry relations, we acknowledge the exogenous sectors affected by the introduction of remanufacturing in the

\footnotetext{
${ }^{9}$ In words, $p$ and $q$ are the monetary fraction of the original market held by the original manufacturing and the remanufacturing sectors, respectively.
} 
economy. This step is necessary because the remanufacturing sector has substantially larger demand for labor, and because the average price of remanufactured products is substantially lower.

First, we deal with the labor provided by households. The payments from each sector to households are indicated in the Labor (or Salaries) sector, a row-vector usually located underneath the matrix of inter-industry relations. Let subscript $\mathrm{n}$ correspond to the original manufacturing sector and subscript $n+1$ correspond to the remanufacturing sector. After a simple augmentation, the row-vector of payments to the Labor sector takes the form

$$
\mathbf{H}_{\text {labor }}=\left[\begin{array}{llll}
\mathrm{H}_{\text {labor, } 1} & \ldots & \mathrm{H}_{\text {labor, }, \mathbf{n}} & \mathrm{H}_{\text {labor, } \mathbf{n}+1}
\end{array}\right]
$$

where $\mathrm{H}_{\text {labor, } n}=\mathrm{H}_{\text {labor, }, \mathrm{n}+1}$ assumes that for each $\$ 1$ of their respective output, remanufacturing and original manufacturing have essentially the same labor requirements.

Step 5 has two parts. First, the final demand is split between the remanufacturing and the original manufacturing sectors. Since remanufacturing items cost less, if the physical demand from both sectors remains the same, an additional income becomes available. Hence, the second part of this step consists in redistributing this income to all sectors. We deal with these issues in sequence:

$$
\mathbf{H}_{\mathbf{Y}}=\left[\begin{array}{c}
\mathrm{H}_{\mathrm{Y}, 1} \\
\mathrm{H}_{\mathrm{Y}, 2} \\
\\
\mathrm{H}_{\mathrm{Y}, \mathrm{n}} \\
\mathrm{H}_{\mathrm{Y}, \mathrm{n}+1}
\end{array}\right]=\left[\begin{array}{cccc}
1 & 0 & \cdots & 0 \\
0 & 1 & & 0 \\
\vdots & & \ddots & \vdots \\
0 & 0 & \cdots & \mathrm{p} \\
0 & 0 & \cdots & \mathrm{q}
\end{array}\right]\left[\begin{array}{c}
\mathrm{Y}_{1} \\
\mathrm{Y}_{2} \\
\vdots \\
\mathrm{Y}_{\mathrm{n}}
\end{array}\right]
$$

Notice that the first $\mathrm{n}-1$ terms in $\mathrm{H}_{\mathrm{Y}}$ and $\mathrm{Y}$ are identical. In addition, the sum of terms in $\mathbf{H}_{\mathbf{Y}}$ is less than the sum of terms in $\mathbf{Y}_{\mathbf{n}}$ as follows:

$$
\begin{aligned}
\sum Y_{j} & =\sum H_{Y, j}+Y_{n}-\left(H_{Y, n}+H_{Y, n+1}\right) \\
& =\sum H_{Y, j}+(1-p-q) Y_{n} \\
\sum Y_{j} & =\sum H_{Y, j}+(1-\delta)(1-p) Y_{n}
\end{aligned}
$$

where the subscript $\mathrm{n}$ corresponds to the original manufacturing sector. That difference between the two sums is the additional income. The complete disaggregation of the final demand requires distributing the additional income as new demand for all sectors. If this distribution is proportional to the final demand observed by each sector, the disaggregated column-vector is obtained with the expression 


$$
\mathbf{B}_{\mathbf{Y}}=\left[\begin{array}{c}
\mathrm{B}_{\mathrm{Y}, 1} \\
\mathbf{B}_{\mathrm{Y}, 2} \\
\mathbf{B}_{\mathrm{Y}, \mathrm{n}} \\
\mathbf{B}_{\mathrm{Y}, \mathrm{n}+1}
\end{array}\right]=\left[\begin{array}{cccc}
\frac{\sum \mathrm{Y}_{\mathrm{j}}}{\sum \mathrm{H}_{\mathrm{Y}, \mathrm{j}}} & 0 & \ldots & 0 \\
0 & \frac{\sum \mathrm{Y}_{\mathrm{j}}}{\sum \mathrm{H}_{\mathrm{Y}, \mathrm{j}}} & & \vdots \\
\vdots & & \ddots & \\
0 & \ldots & & \frac{\sum \mathrm{Y}_{\mathrm{j}}}{\sum \mathrm{H}_{\mathrm{Y}, \mathrm{j}}}
\end{array}\right]\left[\begin{array}{c}
\mathrm{H}_{\mathrm{Y}, 1} \\
\mathrm{H}_{\mathrm{Y}, 2} \\
\mathrm{H}_{\mathrm{Y}, \mathrm{n}} \\
\mathrm{H}_{\mathrm{Y}, \mathrm{n}+1}
\end{array}\right]
$$

Example (cont'd): the final demand for all products in this economy used to be $\$ 1000$. With the introduction of remanufacturing, the demand for widgets is now just $\$ 88$, and the final demand for all products is $\$ 988$. Consequently, there is an additional income of $\$ 12$ available as new demand to all sectors. Once this new demand is distributed, demand for remanufactured widgets is $\$ 1000 * 28 / 988=\$ 28.34$. The demand for virgin widgets is $\$ 1000 * 60 / 988=\$ 60.73$ and the demand for all other products is $\$ 1000 * 900 / 988=\$ 910.93$

Steps 6 and 7 are at the heart of the disaggregation. The distinguishing matrix that accounts for the differences between each original sector and the respective remanufacturing sector does not have to satisfy Eq. (5) because the two sectors do not use the same technology. Hence, the distinguishing matrices take the form:

$$
\begin{aligned}
\mathbf{D} & =\left[\begin{array}{ccccc}
0 & 0 & \cdots & 0 & \mathrm{~d}_{1} \\
\vdots & \vdots & & \vdots & \mathrm{d}_{2} \\
0 & 0 & & 0 & \\
\mathrm{~s}_{1} & \mathrm{~s}_{2} & \cdots & \mathrm{s}_{\mathrm{n}} & \mathrm{d}_{\mathrm{n}} \\
-\mathrm{s}_{1} & -\mathrm{s}_{2} & & -\mathrm{s}_{\mathrm{n}} & \mathrm{d}_{\mathrm{n}+1}
\end{array}\right] \\
\mathbf{D}_{\text {labor }} & =\left[\begin{array}{ccccc}
0 & 0 & \cdots & 0 & \mathrm{~d}_{\text {labor }}
\end{array}\right]
\end{aligned}
$$

Notice that the distinguishing matrices are fully defined by $2 n+2$ parameters. The main difference between the matrices $\mathbf{D}_{\mathbf{W}}$ and $\mathbf{D}$ is that, in our distinguishing matrix, even the column corresponding to original manufacturing sector has $n-1$ elements equal to zero. Hence, all changes in the economy are due to the transfer of part of the demand from the original manufacturing sector to the remanufacturing sector. The lower final cost, lower direct input from the raw material and energy sectors, and higher direct demand from the labor sector drive the impact of this transfer.

Identifying the exact parameter values is a very demanding task. However, economic and physical conditions provide a number of useful bounds that we explore henceforth. The column-vector of parameters $d_{j}$ reflects the difference between the cost structure of the 
remanufacturing and the original manufacturing sectors. A parameter $d_{j}$ is negative for each sector that the remanufacturing industry requires less input. Raw materials and energy are among them. A parameter $d_{j}$ is positive for the few sectors that remanufacturing requires more input, such as the Labor sector and the Transportation Services sector. ${ }^{10}$ In addition, a parameter $d_{j}$ is zero whenever the sector has the same weight in the cost composition of both industry types.

In some instances, the original manufacturing industry must provide additional input to sustain the remanufacturing sector. For example, the original manufacturing industry usually supplies components that cannot be recovered during the remanufacturing operation. In these cases, $d_{n}$ may be positive. Finally, competitive conditions require that the remanufacturing and the original manufacturing industry have similar profitability. ${ }^{11}$ Hence, the sum of the elements in the column vector $\mathbf{B}_{\mathbf{n}}$ and $\mathbf{B}_{\mathbf{n}+1}$ amount to the same value.

$$
\sum_{i=1}^{n+1} B_{i, n}+B_{\text {labor }, n}=\sum_{i=1}^{n+1} B_{i, n+1}+B_{\text {labor }, n+1}
$$

Substituting the respective expressions and simplifying, we can easily obtain the relation:

$$
\sum_{i=1}^{n+1} d_{i}=-d_{\text {labor }}
$$

Eq. 12 says that all deviations in the cost structure of the remanufacturing industry cancel out. In particular, the increased demand for labor compensates the increased demand for transportation and decreased demand for raw materials and energy.

Example (cont'd): Suppose that the widget manufacturing sector used operate with profits worth $20 \%$ of final demand. Hence, its inputs totaled $\$ 80$. In the new scenario, it acquires inputs worth $\$ 48$ (i.e. $80 \%$ of $\$ 60$ ). Moreover, the inputs acquired by the remanufacturing sector are worth $\$ 22.40$ (i.e. $80 \%$ of $\$ 28$ ).

Continuing step 6, we must estimate the row-vector of parameters $\mathrm{s}_{\mathrm{j}}$. They indicate how much each individual sector deviates from the national average regarding its demand from the remanufacturing sector. The $\mathrm{s}_{\mathrm{j}}$ parameters provide the adjustment necessary to acknowledge the difference in the purchasing behavior of different sectors. It is simple to verify that these parameters are bound by the relations:

\footnotetext{
${ }^{10}$ Given the complexity of establishing appropriate reverse logistics, the transportation services sector represents a larger fraction of the inputs to the remanufacturing sector than of inputs to the original manufacturing sector.

${ }^{11}$ From an economic perspective, remanufacturing is a sector that delivers alternative products at a reduced price for the consumer. Since both sectors operate in the same market, in order to coexist in the longer term, one should expect that both industries operate with the same profit margin. If this condition were not satisfied, the least profitable sector would be under substantial competitive disadvantage.
} 


$$
\max \left\{-\mathrm{pA}_{\mathrm{nj}},-1+\mathrm{qA}_{\mathrm{nj}}\right\} \leq \mathrm{s}_{\mathrm{j}} \leq \min \left\{\mathrm{qA}_{\mathrm{nj}}, 1-\mathrm{pA}_{\mathrm{nj}}\right\}
$$

Eq. (13) ensures that all elements in the disaggregated technical coefficient matrix are non-negative. If $s_{j}$ equals its lower bound, sector $\mathrm{j}$ has no inputs from the original sector. Likewise, if $s_{\mathrm{j}}$ equals its upper bound, the sector has no inputs from the remanufacturing sector.

Step 8 generates the disaggregated matrix of technical coefficients as well as the disaggregated row-vector of labor coefficients:

$$
\begin{aligned}
\mathbf{B}=\mathbf{H}+\mathbf{D} & =\left[\begin{array}{ccccc}
\mathrm{H}_{11} & \mathrm{H}_{12} & \cdots & & \mathrm{H}_{1, \mathrm{n}+1} \\
\mathrm{H}_{21} & \mathrm{H}_{22} & & & \\
\vdots & & \ddots & & \vdots \\
\mathrm{H}_{\mathrm{n} 1} & & & \mathrm{H}_{\mathrm{nn}} & \\
\mathrm{H}_{\mathrm{n}+1,1} & \cdots & & & \mathrm{H}_{\mathrm{n}+1, \mathrm{n}+1}
\end{array}\right]+\left[\begin{array}{ccccc}
0 & 0 & \cdots & 0 & \mathrm{~d}_{1} \\
\vdots & & & \vdots & \mathrm{d}_{2} \\
0 & 0 & \cdots & 0 & \vdots \\
\mathrm{s}_{1} & \mathrm{~s}_{2} & & \mathrm{~s}_{\mathrm{n}} & \mathrm{d}_{\mathrm{n}} \\
-\mathrm{s}_{1} & -\mathrm{s}_{2} & \cdots & -\mathrm{s}_{\mathrm{n}} & \mathrm{d}_{\mathrm{n}+1}
\end{array}\right] \\
\mathbf{B}_{\text {labor }} & =\mathbf{H}_{\text {labor }}+\mathbf{D}_{\text {labor }} \\
& =\left[\begin{array}{lllll}
\mathrm{H}_{\text {labor, }, 1} & \cdots & \mathrm{H}_{\text {labor, }} & \mathrm{H}_{\text {labor, }, \mathrm{n}+1}
\end{array}\right]+\left[\begin{array}{lllll}
0 & \cdots & 0 & \mathrm{~d}_{\text {labor, }, \mathrm{n}+1}
\end{array}\right]
\end{aligned}
$$

where the elements in $\mathbf{H}$ and $\mathbf{H}_{\text {labor }}$ are obtained according to Eqs. (2) and (8), respectively.

Steps 9 and 10 are necessary to obtain the matrix of inter-industry flows. Using the result of Eq. (14), the Leontief inverse is simply (I-B) ${ }^{-1}$. If matrix $\mathbf{B}$ is of dimension smaller than $50 \times 50$, this inversion can be performed in simple spreadsheet packages. Consequently, the disaggregated total output column follows

$$
\mathbf{B}_{\mathbf{X}}=(\mathbf{I}-\mathbf{B})^{-1} \mathbf{B}_{\mathbf{Y}}
$$

Finally, we wish to obtain the disaggregated matrix of inter-industry transactions and the row-vector of labor inputs. They satisfy the expressions

$$
\begin{aligned}
\mathrm{W}_{\mathrm{ij}} & =\mathrm{B}_{\mathrm{ij}} * \mathrm{~B}_{\mathrm{X}, \mathrm{j}} \\
\mathrm{W}_{\mathrm{labor}, \mathrm{j}} & =\mathrm{B}_{\mathrm{labor}, \mathrm{j}} * \mathrm{~B}_{\mathrm{X}, \mathrm{j}}
\end{aligned}
$$

The results from Eqs. (16) allow us to evaluate the actual changes in the total output of each other sector given the introduction of the remanufacturing sector in the economy. Let

$$
\rho_{\mathrm{i}}=\mathrm{B}_{\mathrm{X}, \mathrm{i}} / \mathrm{X}_{\mathrm{i}}-1
$$

be the ratio between the total output of sector $i$ with and without remanufacturing. It indicates the loss (or gain) in the output of that sector. 
We observe these changes using the input-output tables for the French economy in 1991 (INSEE (1995)). The original table contains 98 sectors. For the purpose of this illustration, it was aggregated into 30 sectors. We took adequate care to ensure that the aggregation was such that any distortion in the analysis would be minimal. The aggregated sectors generally had very low inputs into the manufacturing sectors. Moreover, the aggregation allows illustrating the model using spreadsheet software. Table 2 and Table 3 disclose the 30 sectors.

\section{INSERT Table 2 and Table 3 ABOUT HERE}

\section{The impact of remanufacturing tires, computers and automobiles}

Tire retreading is a healthy business in some countries, particularly in the replacement market for some industrial applications. However, its penetration in the passenger car market has reduced steadily and represents less than $10 \%$ of the tire replacement market in most OECD countries Ferrer (1997b). In the French input-output tables, this business is pooled in the Tire and Rubber sector (BDS 52). Here, we disregard the penetration that retreaded tires already have, assume that the data on the tire and rubber industry refer exclusively to new tires, to measure the likely impact of a first time introduction of retreaded tires.

In our 30-sector aggregation, the Tire and Rubber sector accounts for a total output of $55.69 \times 10^{9} \mathrm{FF}$ in 1991 . It is the $26^{\text {th }}$ largest sector in this economy, measured by its total output, or the $24^{\text {th }}$ largest sector, measured by its inputs from other sectors in the inter-industry matrix. The impact of introducing a tire retreading sector depends on its total output in the economy.

Comment: If the sector is split under the parameters $p=0.5$ and $\delta=0.7$, the total output of each sector would be around $28 \times 10^{9} \mathrm{FF}$ and $20 \times 10^{9} \mathrm{FF}$, respectively. They would be among the two smallest sectors in the table. Other parameter choices would have similar implications. Hence, we should not expect a large impact.

It is well known that the automobile sector (BDS 311) has a great influence over the general economy, because it draws large inputs from many sectors. It includes automobiles, trucks, motorcycles, mopeds and bicycles In our 30-sector aggregation of the French economy, 12 sectors manufacture durable goods. The total output from the automobile sector is the $5^{\text {th }}$ of all sectors but the second largest among durable goods sectors. In fact, the automobile industry receives inputs from 23 sectors. Remanufacturing automobiles has a strong first-order effect in most of them and significant higher-order effects in many others. For this reason, this analysis is likely to have a significant impact in the economy.

The computer manufacturing sector (BDS 27) includes portable computers, mainframes, peripherals, and some office equipment. In this 30-sector aggregation, it receives inputs from 20 sectors. Since computer manufacturing is a very international business, most computers actually 
consumed in France are manufactured abroad. For this reason, it is just the $23^{\text {th }}$ largest sector in this aggregation, the $7^{\text {th }}$ among the 12 sectors that manufacture durable goods. However, since the input-output table only refers to the inter-industry transactions occurring within a region - in this case, France - an eventual remanufacturing industry is likely to process (or produce) more units than were originally manufactured within the country. We do not deal with this possibility now. ${ }^{12}$

For the sake of simplicity, we assume that the market absorbs all of the output from the remanufacturing sectors. Producers of recycled paper know that this is not always true. The stochastic aspects of input availability and demand for outputs have a significant influence over the economics of any product recovery activity. However, since our interest is in understanding the impact of successful remanufacturing sectors, we believe that we can concentrate in the basic model, without uncertainty.

\subsection{Parameter choices}

In what follows we disaggregate the $30 \times 30$ input-output table of the French economy to examine the impact of remanufacturing tires, computers and automobiles. The individual impacts are driven by the parameters defining the respective distinguishing matrix. Hence, we examine a number of scenarios, corresponding to different levels of market share, and different levels of price discount offered by the remanufactured products. In all scenarios, the four assumptions described in the previous section are strictly observed. Table 4 describes these scenarios:

\section{INSERT Table 4 ABOUT HERE}

If the market share secured by the original manufacturing sector since the introduction of remanufacturing is $p$, then the final demand for the products from the original manufacturing sector is multiplied by p. Moreover, in the augmented matrix, the row corresponding to the inputs from original manufacturing to all other sectors has all elements multiplied by the same factor $p$. (Subsequently, the augmented technical coefficients are adjusted by the parameters $s_{j}$ in the distinguishing matrix, as described in the previous section.)

The market share of the remanufactured good is 1-p (as a fraction of the physical market), but each product is sold at the discount price $\delta<1$. Therefore, in the augmented matrix, the row corresponding to the remanufacturing sector's output is obtained by multiplying each element of the original row by $\delta^{*}(1-\mathrm{p})$. Although the physical number of goods sold is maintained, the monetary value of the sales secured by the two sectors combined is less than the original sales level. These scenarios contain a broad coverage of "reasonable" values that may occur in the

\footnotetext{
${ }^{12}$ One could deal with this phenomenon including the Import sector in the analysis. This would account for the substitution of some inputs from this source by the remanufactured units produced in the country.
} 
economy, if remanufacturing becomes a significant competitor of the original manufacturing sector. They were chosen as follows:

- Market shares of $40 \%$ and $60 \%$ correspond to situations where both the remanufacturing and original manufacturing sectors hold significant participation in the economy. Values smaller than $40 \%$ are not reasonable: it would imply that the original manufacturing sector would gradually disappear. Values above that would not satisfy the problem's original condition that remanufacturing gains a significant share of the market.

- A value of $\delta=0.7$ implies that the remanufactured good is sold for a $40 \%$ discount over the price of the originally manufactured good. In France, remanufactured photocopiers are sold for roughly $40 \%$ discount over the price of new photocopiers of the same manufacturer $(\delta=0.6)$. The additional scenarios with $\delta=0.5$ (50\% discount) and $\delta=0.7$ (30\% discount) cover a reasonable neighborhood of the observed value.

- The labor multiplier is bound by practical limitations. It cannot be lower than 1.0 (since it would imply that remanufacturing is less labor intensive than original manufacturing). These tables show that in these sectors labor inputs range from $22 \%$ (in the automobile sector) to $42 \%$ of total inputs (in the tire sector). In order to allow the remanufacturing and the original manufacturing sectors to have the same profitability, the labor multiplier cannot be greater than roughly 2.3. Labor increases as a substitution of inputs that are not needed in remanufacturing, but not all inputs can be substituted. This constitutes a practical upper bound of roughly 2.0 in the labor multiplier. Hence, 1.2, 1.5 and 1.8 seem to be good representatives of the feasible range $(1.0-2.0)$.

The relationship between remanufacturing and labor-intensity is complex. In a typical mass production item (such as automobile engine) the fixed cost of a plant, including design and engineering, represents an investment of about $\$ 1$ billion. The plant might produce about 10 million units over its lifetime, for a fixed cost of $\$ 100$ per unit and a variable cost of perhaps $\$ 2000$ per unit. It follows that the first unit costs about 500,000 times as much as the 10 millionth unit. On the other hand, when design and engineering are not considered, the cost differential is much lower. The cost of making all parts of a unique prototype engine in a machine shop is estimated to be around 200 times the variable cost of a mass produced version. Taking the latter as typical, we have an approximate relationship for unit cost vs. lot size:

$$
\text { unit cost }=1+200 / \mathrm{N}
$$

The key point here is that it is roughly ten times more expensive to manufacture (or repair) a single unit than a lot of 10 . Increasing the lot size to 1000 cuts unit costs again by another factor of twenty. Beyond that point, the advantages of increasing lot size are negligible. 
Obviously remanufacturing is inherently much less able to capture large scale advantages of standardized mass production than primary manufacturing. A remanufacturing operation necessarily deals with a number of different models and ages, each of which involves different setups and tools. The heterogeneous input stream must clearly be sorted into lots before further operations are undertaken, and since very small lots are uneconomic, a significant amount of storage space may be needed as lots accumulate to critical size. On the other hand, as remanufacturing becomes more the rule than the exception, production runs will increase. Developments in computer-integrated manufacturing and programmable automation have reduced the disadvantage of small lots, and this trend can be expected to continue (see Ayres and Butcher (1993). Finally, successive models can be designed to minimize differences in disassembly, setup and processing costs. Thus, the scale-related penalty of remanufacturing is expected to reduce in the course of time.

Most of these added costs (of processing small lots) are labor costs. Thus, as remanufacturing increases, direct employment increases. Clearly, these added costs impose a limit on the economic feasibility of remanufacturing. Although environmental benefits may be significant, the primary concern for a firm must be its own cost structure. It can justify remanufacturing only if other cost reductions compensate for the higher labor requirements.

Overall, we have limited our analysis to three levels of labor cost increase, ranging from $20 \%(\lambda=1.2)$ to $80 \%(\lambda=1.8)$. It means that, if the labor increase in the remanufacturing sector is $\lambda$, than each monetary unit of output from this sector requires labor inputs equivalent to those required by the original manufacturing sector multiplied by $\lambda$. Since the inputs from the Transport Services sector are also increased, and the total inputs from all sectors are the same as in the original manufacturing sector, there will be a substantial decrease in some of the other inputs. (This trade-off characterizes the remanufacturing process, where physical inputs such as raw materials or semi-finished goods are traded against labor time in recovering the used goods.)

The objective here is to identify directions of change, using the original economy as the benchmark. Combining these parameters, we expect to cover the space of possible outcomes, under the assumptions stated herein.

Venta and Wolsky (1978) have examined the aggregate demand for labor and energy in the automobile component remanufacturing sector. There, the purpose is to obtain a measure of total energy and labor consumed by the sector. This work differs from their analysis because it is a comparison between two economies (with and without remanufacturing). However, it provides some guidance in terms of the sectors directly affected by automobile component remanufacturing, as well as the magnitude of these effects. In addition, Das et al. (1995) provides information regarding the type and quantity of raw materials and the amount of energy required in automobile production. Studies by Ferrer $(1997 \mathrm{a} ; 1997 \mathrm{~b})$ analyzed the economics of 
remanufacturing tires and personal computers, respectively. Information from these studies was useful in estimating the input requirements of hypothetical remanufacturing sectors.

A complete disaggregation requires estimating the parameters that distinguish the sectors according to the technology used $\left(\mathrm{d}_{\mathrm{j}}\right)$ and the parameters that distinguish them according to their markets $\left(\mathrm{s}_{\mathrm{j}}\right)$. Unfortunately, we have little information available that could be useful determining the market deviation parameters. Ideally, remanufactured products have as good a performance as originally manufactured products. Hence, if they cost less, "utilitarian" sectors would rather buy from the remanufactured sector than from the original manufacturing sector, if available. For example, tires purchased by the agricultural sector would come from the tire retreading industry, rather than from the new tires industry. On the other hand, if the good is a direct input of an original product (e.g., tires as a production input in automobile manufacturing), that sector will only buy the original version. We used that logic as the basis for estimating the market deviation parameters.

\subsection{The impact of developing remanufacturing sectors}

In this analysis, we disaggregate a 30-sector table to introduce three new sectors: Computer Remanufacturing, Automobile Remanufacturing and Tire Retreading. Table 4 suggested evaluating two different levels of market share, three levels of price discount and three levels of labor requirements. Considering the French economy in 1991 as an appropriate benchmark, we evaluated all 18 possible scenarios derived from the table of parameters.

The development of the remanufacturing sectors causes the changes in the output of the other sectors, shown in Table $5 .^{13}$ The table shows two columns of changes. The sectors that lose most inter-industry transactions are usually the ones providing raw materials and components to the three sectors analyzed: foundry and metal-working (PDS20-1), iron and steel products (PDS09-1), plastic products (PDS53) and electric and electronic products (PDS28, 291). They are also the sectors with greatest reduction in total output.

\section{INSERT Table 5 Table 6 ABOUT HERE}

In addition, Table 6 shows that each original sector suffered different changes in interindustry and total output. In this scenario, the final demand for each of the original manufacturing sector was reduced by $50 \%(p=0.5)$. Other things equal, one might expect that their inter-industry transactions observe changes of the same magnitude. However, each sector experienced a different reaction. Reduction in the inter-industry transactions of the tire industry was closer to $56 \%$ (larger than $50 \%$ ). It happens that the tire industry depends largely on its transactions with the automobile industry. That greater reduction in the transactions of the tire

${ }^{13}$ Scenario shown in Tables 5 and 6: $\lambda=1.5, p=0.5, \delta=0.5$. 
industry is caused by a large second-order effect from the automobile industry. Contrariwise, the automobile and the computer industries observed a reduction in their inter-industry transactions of $41 \%$ and $46 \%$, respectively. They depend very little in the transactions with the other industries where we created a remanufacturing dual. Hence, the second-order effects are not as significant. Moreover, all three original manufacturing sectors become large suppliers of their respective remanufacturing sectors, as the main source of components, dampening the reduction of their final demand.

\section{INSERT Table 7 ABOUT HERE}

One of our concerns was the impact of remanufacturing in the demand for labor. There is a persistent argument whether remanufacturing activities have positive or negative impact on demand for labor. Although remanufacturing per se is labor intensive, it reduces the needs for several outputs that are labor intensive as well. Table 7 shows the changes in labor output under 18 scenarios. Each scenarios required more labor, ranging from $0.21 \%$ to $0.82 \%$ increase in labor output. We derived the following linear regression model relating the changes in labor with economic parameters:

$$
\% \text { LaborChange }=(0.83+0.42 * \lambda-1.08 * \mathrm{p}-0.71 * \delta) \%
$$

Example: In the scenario where $\lambda=1.5, p=0.5$ and $\delta=0.5$, the formula indicates that demand for labor would increase by $0.494 \%$. Calculations disaggregating the original input-output tables would suggest an increase of $0.489 \%$.

The greatest labor increases occur when the remanufacturing sector has large market share and requires more labor (at the expense of inputs from many other sectors). Moreover, labor output increases with the price discounts adopted by the remanufacturing sector. This implies that remanufacturing provides more direct and indirect labor than original manufacturing.

Finally, there is a concern whether remanufacturing operations promote growth or not. Table 8 sheds the light over this issue. By construction, we had imposed that the sum of final demands from all sectors remained constant. This was accomplished by distributing the income saved with the purchase from the remanufacturing sector among all sectors (as explained in the previous section). However, as we let the inter-industry transactions accommodate the new economic structure, we observe a generalized reduction of inter-industry activity, ranging from $0.32 \%$ to $-0.75 \%$. It is a point of debate whether this reduction is "healthy" for the economy or not. One may argue that for a fixed level of final demand, fewer inter-industry transactions imply in a more efficient economy. If that argument is correct, we might say that a remanufacturing economy is more efficient, even before we consider the environmental implications. 
INSERT Table 8 ABOUT HERE

\section{Conclusion}

The purpose of this study is three-fold: to develop a methodology for disaggregating the inputoutput tables to incorporate remanufacturing sectors as competitors of existing manufacturing sectors; to illustrate the methodology using a 30x30 version of the input-output tables for the French economy in 1991; to identify the direction of changes in the demand for labor and in the total inter-industry transactions given the development of remanufacturing sectors.

The methodology is simple, requiring the estimation of $2 n+2$ parameters for each remanufacturing sector introduced in the table. They regard the difference in the technology used by the remanufacturing sector ( $n+1$ parameters), the different purchasing preferences that each sector has regarding the remanufactured product (n parameters) and the different need for labor ( 1 parameter). For the illustration, we estimated some parameters based on previous studies. However, market-related parameters could not be evaluated very precisely. Their estimation was based on the most-likely buying behavior of the other sectors. (Further research is required in that domain.) Finally, the analysis of the French economy led to the following observations:

1. Remanufacturing activity promotes demand for labor.

2. Remanufacturing activity reduces the level of inter-industry transaction.

3. Suppliers of sectors subject to competition from remanufacturing sectors have their interindustry transaction significantly reduced. That situation is exacerbated if the sector is also subject to remanufacturing activity. 


\section{TABLES}

Table 1: Procedure for disaggregation due to the introduction of remanufacturing sectors

\begin{tabular}{|c|c|}
\hline Step and Description & Pre-requisites \\
\hline 1. Estimate physical market share of original sector (p) & \\
\hline $\begin{array}{l}\text { 2. Estimate relative price exercised in the remanufacturing } \\
\text { sector }(\delta)\end{array}$ & \\
\hline 3. Augment row-vector of labor coefficients $\left(\mathbf{H}_{\text {labor }}\right)$ & Original vector of labor coefficients \\
\hline 4. Augment matrix of technical coefficients $(\mathbf{H})$ & $\begin{array}{l}\text { Original matrix of technical } \\
\text { coefficients (A) } \\
\text { Step } 1 \\
\text { Step } 2\end{array}$ \\
\hline $\begin{array}{l}\text { 5. Augment final demand column }\left(\mathbf{H}_{\mathbf{Y}}\right) \text { and derive } \\
\text { disaggregated final demand column }\left(\mathbf{B}_{\mathbf{Y}}\right)\end{array}$ & $\begin{array}{l}\text { Original final demand column (Y) } \\
\text { Step } 1 \\
\text { Step } 2\end{array}$ \\
\hline $\begin{array}{l}\text { 6. Estimate technological difference parameters }\left(d_{j}\right) \text { and } \\
\text { market share deviation parameters }\left(s_{j}\right)\end{array}$ & \\
\hline $\begin{array}{l}\text { 7. Derive distinguishing matrix of technical coefficients } \\
\text { (D) and distinguishing vector of labor coefficients } \\
\text { (D labor) }\end{array}$ & Step 6 \\
\hline $\begin{array}{l}\text { 8. Derive disaggregated matrix of technical coefficients } \\
\text { (B) and disaggregated vector of labor coefficients } \\
\left.\text { (B } \mathbf{B}_{\text {labor }}\right)\end{array}$ & $\begin{array}{l}\text { Step } 3 \\
\text { Step } 4 \\
\text { Step } 7\end{array}$ \\
\hline $\begin{array}{l}\text { 9. Derive the disaggregated Leontief matrix (I-B) and its } \\
\text { inverse }\end{array}$ & Step 8 \\
\hline 10. Derive disaggregated total output column $\left(\mathbf{B}_{\mathbf{X}}\right)$ & $\begin{array}{l}\text { Step } 5 \\
\text { Step } 9\end{array}$ \\
\hline $\begin{array}{l}\text { 11. Derive disaggregated matrix of inter-industry flows } \\
\left.\text { (W) and disaggregated vector of labor inputs ( } \mathbf{W}_{\text {labor }}\right)\end{array}$ & $\begin{array}{l}\text { Step } 8 \\
\text { Step } 10 \\
\end{array}$ \\
\hline
\end{tabular}


Table 2: Purchasing sector aggregation from the original 96x98 table

\begin{tabular}{|c|c|c|c|c|c|}
\hline Codes & 30-Sector Aggregation & \begin{tabular}{|l|} 
Nr. of \\
Sectors in the \\
Aggregation \\
\end{tabular} & Codes & 30-Sector Aggregation & \begin{tabular}{|l} 
Nr. of \\
Sectors in the \\
Aggregation
\end{tabular} \\
\hline$\overline{\text { BDS01-03 }}$ & $\begin{array}{l}\text { Agriculture, forestry and } \\
\text { fishing }\end{array}$ & 3 & $\begin{array}{l}\mathrm{BDS} 312 \\
32-3\end{array}$ & $\begin{array}{l}\text { Rail equipment. shipyards } \\
\text { and airplane construction }\end{array}$ & 3 \\
\hline BDS04-5 & $\begin{array}{l}\text { Coal mining, oil and gas } \\
\text { production, refining }\end{array}$ & 5 & $\mathrm{BDS} 34$ & $\begin{array}{l}\text { Instrument and precision } \\
\text { material industry }\end{array}$ & 1 \\
\hline BDS06-8 & $\begin{array}{l}\text { Electricity, gas and water } \\
\text { utilities }\end{array}$ & 3 & BDS35-49 & $\begin{array}{l}\text { Food, beverage, tobacco, } \\
\text { textile, leather and wood } \\
\text { industry }\end{array}$ & 20 \\
\hline BDS09-1 & Iron and steel industry & 3 & BDS50 & Paper and pulp industry & 1 \\
\hline BDS12-3 & $\begin{array}{l}\text { Extraction and metallurgy of } \\
\text { nonferrous metals }\end{array}$ & 2 & BDS51 & Press & 1 \\
\hline$\overline{\mathrm{BDS} 14}$ & Production of other minerals & 1 & BDS52 & Tire and rubber industry & 1 \\
\hline BDS15-6 & $\begin{array}{l}\text { Construction material, } \\
\text { ceramics and glass industry }\end{array}$ & 2 & BDS53 & Plastic industry & 1 \\
\hline$\overline{\text { BDS17-9 }}$ & $\begin{array}{l}\text { Chemical and } \\
\text { pharmaceutical industry }\end{array}$ & 4 & BDS54 & Other industries & 1 \\
\hline BDS20-1 & Foundry and metal-working & 2 & BDS55 & $\begin{array}{l}\text { Civil engineering and } \\
\text { construction }\end{array}$ & 1 \\
\hline BDS22-5 & $\begin{array}{l}\text { Agricultural, public works } \\
\text { and machine tool industry }\end{array}$ & 4 & BDS56 & Product recovery services & 1 \\
\hline$\overline{B D S 26}$ & Armament industry & 1 & BDS65 & Automobile repair and sales & 1 \\
\hline BDS27 & $\begin{array}{l}\text { Office equipment and } \\
\text { computer industry }\end{array}$ & 1 & BDS66 & Other repair services & 1 \\
\hline BDS28-291 & $\begin{array}{l}\text { Electrical and electronic } \\
\text { equipment industry }\end{array}$ & 2 & BDS67 & Hotels and restaurants & 1 \\
\hline BDS292-30 & $\begin{array}{l}\text { Electronic home products } \\
\text { and home appliance industry }\end{array}$ & 2 & BDS68-4 & Transport services & 7 \\
\hline$\overline{\mathrm{BDS} 311}$ & $\begin{array}{l}\text { Automobile, motorcycle and } \\
\text { bicycle industry }\end{array}$ & 1 & $\begin{array}{l}\text { BDS57-64, } \\
75-98\end{array}$ & Other services & 21 \\
\hline
\end{tabular}


Table 3: Input products aggregation from the original $98 \times 98$ table

\begin{tabular}{|c|c|c|c|c|c|}
\hline$\overline{\text { Codes }}$ & 43-Sector Aggregation & \begin{tabular}{|l} 
Nr. of \\
Sectors in the \\
Aggregation
\end{tabular} & Codes & 43-Sector Aggregation & \begin{tabular}{|l|} 
Nr. of \\
Sectors in the \\
Aggregation
\end{tabular} \\
\hline$\overline{\text { PDS01-3 }}$ & $\begin{array}{l}\text { Agricultural, forestry and } \\
\text { fishing products }\end{array}$ & 3 & PDS312-3 & $\begin{array}{l}\text { Trains, ships, airplanes and } \\
\text { assimilated products }\end{array}$ & 3 \\
\hline PDS04-5 & $\begin{array}{l}\text { Coal, coke, petroleum and } \\
\text { natural gas }\end{array}$ & 5 & PDS34 & $\begin{array}{l}\text { Instruments and precision } \\
\text { material }\end{array}$ & 1 \\
\hline PDS06-8 & Electricity, gas and water & 3 & PDS35-49 & $\begin{array}{l}\text { Food, beverages, tobacco, } \\
\text { textile, leather and wood } \\
\text { products }\end{array}$ & 20 \\
\hline PDS09-1 & $\begin{array}{l}\text { Iron ore, iron and steel } \\
\text { products }\end{array}$ & 3 & PDS50 & Paper and pulp & 1 \\
\hline PDS12-3 & $\begin{array}{l}\text { Nonferrous minerals, metals } \\
\text { and semifinished products }\end{array}$ & 2 & PDS51 & Printed material & 1 \\
\hline$\overline{\text { PDS14 }}$ & Other minerals & 1 & PDS52 & $\begin{array}{l}\text { Tires and other rubber } \\
\text { products }\end{array}$ & 1 \\
\hline PDS15-6 & $\begin{array}{l}\text { Construction material, } \\
\text { ceramics and glass products }\end{array}$ & 2 & PDS53 & Plastic products & 1 \\
\hline PDS17-9 & $\begin{array}{l}\text { Chemical and pharmaceutical } \\
\text { products }\end{array}$ & 4 & PDS54 & Other industrial products & 1 \\
\hline PDS20-1 & $\begin{array}{l}\text { Foundry and metalworking } \\
\text { products }\end{array}$ & 2 & PDS55 & $\begin{array}{l}\text { Civil engineering and } \\
\text { construction products }\end{array}$ & 1 \\
\hline PDS22-25 & $\begin{array}{l}\text { Agricultural, public works } \\
\text { and industrial equipment }\end{array}$ & 4 & PDS56 & Recovered products & 1 \\
\hline PDS26 & Armaments & 1 & PDS65 & Automobile repair and sales & 1 \\
\hline PDS27 & $\begin{array}{l}\text { Office and computer } \\
\text { equipment }\end{array}$ & 1 & PDS66 & Other repairs & 1 \\
\hline PDS28, 291 & $\begin{array}{l}\text { Electrical and electronic } \\
\text { equipment }\end{array}$ & 2 & PDS67 & Hotels and restaurants & 1 \\
\hline PDS292,30 & $\begin{array}{l}\text { Electronic home products and } \\
\text { hone appliances }\end{array}$ & 2 & PDS68-4 & Transport services & 7 \\
\hline PDS311 & $\begin{array}{l}\text { Automobiles, motorcycles } \\
\text { and bicycles }\end{array}$ & 1 & PDS75-98 & Other services & 19 \\
\hline
\end{tabular}


Table 4: Economic parameters for evaluating remanufacturing effects

\begin{tabular}{lcc}
\hline Parameter Definitions & Symbols & Levels \\
\hline $\begin{array}{l}\text { Market share secured by the original manufacturing sector. } \\
\text { (previous market share }=1 \text { ) }\end{array}$ & $\mathrm{p}$ & 0.4 and 0.6 \\
\hline $\begin{array}{l}\text { Relative price of the remanufactured good. } \\
\text { (price of originally manufactured good }=1 \text { ) }\end{array}$ & $\delta$ & $0.5,0.6$ and 0.7 \\
\hline $\begin{array}{l}\text { Labor input in Remanufacturing sector. } \\
\text { (Labor sector input in original manufacturing }=1)\end{array}$ & $\lambda$ & $1.2,1.5$ and 1.8 \\
\hline
\end{tabular}


Table 5: Sectoral changes due to the introduction of remanufacturing sectors

\begin{tabular}{|c|c|c|c|c|c|}
\hline Sector code & Sector description & $\begin{array}{l}\text { Changes in } \\
\text { Total Inter- } \\
\text { industry } \\
\text { Demand }\end{array}$ & Rank & $\begin{array}{l}\text { Changes in } \\
\text { Total Output }\end{array}$ & Rank \\
\hline PDS01-3 & Agricultural, forestry and fishing products & $1.13 \%$ & 1 & $1.29 \%$ & 6 \\
\hline PDS04-5 & Coal, coke, petroleum and natural gas & $0.42 \%$ & 12 & $0.93 \%$ & 11 \\
\hline PDS06-8 & Electricity, gas and water & $-0.66 \%$ & 18 & $0.39 \%$ & 19 \\
\hline PDS09-1 & Iron ore, iron and steel products & $-6.28 \%$ & 27 & $-3.90 \%$ & 27 \\
\hline PDS12-3 & $\begin{array}{l}\text { Nonferrous minerals, metals and semifinished } \\
\text { products }\end{array}$ & $-0.93 \%$ & 19 & $-0.30 \%$ & 24 \\
\hline PDS14 & Other minerals & $-0.54 \%$ & 17 & $0.04 \%$ & 22 \\
\hline PDS15-6 & $\begin{array}{l}\text { Construction material, ceramics and glass } \\
\text { products }\end{array}$ & $0.11 \%$ & 14 & $0.36 \%$ & 20 \\
\hline PDS17-9 & Chemical and pharmaceutical products & $-1.13 \%$ & 22 & $0.36 \%$ & 21 \\
\hline $\mathrm{PDS} 20-1$ & Foundry and metalworking products & $-6.69 \%$ & 28 & $-4.20 \%$ & 28 \\
\hline PDS22-25 & $\begin{array}{l}\text { Agricultural, public works and industrial } \\
\text { equipment }\end{array}$ & $-0.99 \%$ & 20 & $0.86 \%$ & 13 \\
\hline PDS26 & Armaments & $0.80 \%$ & 4 & $1.14 \%$ & 8 \\
\hline PDS28, 291 & Electrical and electronic equipment & $-1.79 \%$ & 24 & $-0.05 \%$ & 23 \\
\hline PDS292, 30 & Electronic home products and hone appliances & $0.69 \%$ & 5 & $1.41 \%$ & 1 \\
\hline PDS312-3 & Trains, ships, airplanes and assimilated products & $0.99 \%$ & 2 & $1.29 \%$ & 5 \\
\hline PDS34 & Instruments and precision material & $-1.95 \%$ & 25 & $0.81 \%$ & 16 \\
\hline PDS35-49 & $\begin{array}{l}\text { Food, beverages, tobacco, textile, leather and } \\
\text { wood products }\end{array}$ & $0.25 \%$ & 13 & $1.18 \%$ & 7 \\
\hline PDS50 & Paper and pulp & $0.59 \%$ & 6 & $0.86 \%$ & 14 \\
\hline PDS51 & Printed material & $0.54 \%$ & 7 & $0.90 \%$ & 12 \\
\hline PDS53 & Plastic products & $-3.99 \%$ & 26 & $-2.36 \%$ & 26 \\
\hline PDS54 & Other industrial products & $0.83 \%$ & 3 & $1.41 \%$ & 3 \\
\hline PDS55 & Civil engineering and construction products & $0.48 \%$ & 10 & $1.41 \%$ & 2 \\
\hline PDS56 & Recovered products & $-1.48 \%$ & 23 & $-1.47 \%$ & 25 \\
\hline PDS65 & Automobile repair and sales & $-0.05 \%$ & 15 & $1.02 \%$ & 9 \\
\hline PDS66 & Other repairs & $-1.10 \%$ & 21 & $0.93 \%$ & 10 \\
\hline PDS67 & Hotels and restaurants & $0.51 \%$ & 8 & $1.35 \%$ & 4 \\
\hline PDS68-4 & Transport services & $0.47 \%$ & 11 & $0.84 \%$ & 15 \\
\hline PDS75-98 & Other services & $-0.26 \%$ & 16 & $0.74 \%$ & 17 \\
\hline $\mathrm{R} 10$ & Salaries & $0.49 \%$ & 9 & $0.49 \%$ & 18 \\
\hline
\end{tabular}


Table 6: Sectoral changes due to the introduction of remanufacturing sectors (cont'd)

\begin{tabular}{|l|l|c|c|}
\hline Sector code & Original manufacturing sector description & $\begin{array}{c}\text { Changes in } \\
\text { Total Inter- } \\
\text { industry } \\
\text { Demand }\end{array}$ & $\begin{array}{c}\text { Changes in } \\
\text { Total Demand }\end{array}$ \\
\hline PDS311 & Automobiles, motorcycles and bicycles & $-40.7 \%$ & $-47.8 \%$ \\
\hline PDS27 & Office and computer equipment & $-45.5 \%$ & $-48.3 \%$ \\
\hline PDS52 & Tires and other rubber products & $-55.8 \%$ & $-52.7 \%$ \\
\hline
\end{tabular}

Table 7: Changes in labor output under different economic scenarios

\begin{tabular}{l|c|c|c|c|c|c}
\hline & \multicolumn{3}{|c|}{$p=0.4$} & \multicolumn{3}{c|}{$p=0.6$} \\
\hline & $\lambda=1.2$ & $\lambda=1.5$ & $\lambda=1.8$ & $\lambda=1.2$ & $\lambda=1.5$ & $\lambda=1.8$ \\
\hline$\delta=0.5$ & $0.56 \%$ & $0.69 \%$ & $0.82 \%$ & $0.35 \%$ & $0.44 \%$ & $0.52 \%$ \\
$\delta=0.6$ & $0.45 \%$ & $0.60 \%$ & $0.75 \%$ & $0.28 \%$ & $0.38 \%$ & $0.48 \%$ \\
$\delta=0.7$ & $0.34 \%$ & $0.51 \%$ & $0.69 \%$ & $0.21 \%$ & $0.33 \%$ & $0.45 \%$ \\
\hline
\end{tabular}

Table 8: Changes in total inter-industry transactions under different economic scenarios

\begin{tabular}{l|l|l|l|l|l|l}
\hline & \multicolumn{3}{|c|}{$\mathrm{p}=0.4$} & \multicolumn{3}{c}{$\mathrm{p}=0.6$} \\
\hline & $\lambda=1.2$ & $\lambda=1.5$ & $\lambda=1.8$ & $\lambda=1.2$ & $\lambda=1.5$ & $\lambda=1.8$ \\
\hline$\delta=0.5$ & $-0.54 \%$ & $-0.65 \%$ & $-0.75 \%$ & $-0.40 \%$ & $-0.47 \%$ & $-0.54 \%$ \\
$\delta=0.6$ & $-0.51 \%$ & $-0.63 \%$ & $-0.76 \%$ & $-0.37 \%$ & $-0.45 \%$ & $-0.53 \%$ \\
$\delta=0.7$ & $-0.46 \%$ & $-0.61 \%$ & $-0.75 \%$ & $-0.32 \%$ & $-0.42 \%$ & $-0.52 \%$ \\
\hline
\end{tabular}

\section{References}

Ayres, Robert U. and Duane C. Butcher (1993). "The flexible factory revisited." In American Scientist 81: pages 448-459.

Ayres, Robert U., Geraldo Ferrer and Tania Van Leynseele (1997). "Eco-Efficiency, Asset Recovery and Remanufacturing." In European Management Journal 15(5): pages 557-574.

Burress, David (1994). "Homeomorphism between Leontief and Cobb-Douglas Input-Output Models." In Economics Letters 44(1/2): pages 49-53.

Chen, Chiung-Yao and Alfred Vella (1994). "Estimating the Economic Costs of Electricity Shortages Using Input-Output Analysis: The Case of Taiwan." In Applied Economics 26(11): pages 1061-1069.

Common, M. S. and P. McPherson (1982). "A Note of Energy Requirements: Calculations Using 1968 and 1974 UK Input-Output Tables.” In Energy Policy 10(1): pages 42-48. 
Das, Sujit, et al. (1995). "Automobile Recycling in the United States: Energy Impacts and Waste Generation." In Resources, Conservation and Recycling 14: pages 265-284.

Davis, H. Craig (1987). “Accounting for Technical Substitution in the Input-Output Model." In Technological Forecasting and Social Change 32(4): pages 361-371.

Driver, Ciaran (1994). "Structural Change in the UK 1974-1984: An Input Output Analysis." In Applied Economics 26(2): pages 153-158.

Feldman, S. J., D. McClain and K. Palmer (1987). "Sources of Structural changes in the United States, 1963-78: An Input-Output Perspective." In The Review of Economics and Statistics 69(3): pages 503-510.

Ferrer, Geraldo (1997a). "The Economics of Personal Computer Remanufacturing." In Resources, Conservation and Recycling 21: pages 79-108.

Ferrer, Geraldo (1997b). "The Economics of Tire Remanufacturing." In Resources, Conservation and Recycling 19(4): pages 221-255.

Hannan, Michael J. and Adam Z. Rose (1988). "The Policy-Cost Index Approach to Modeling Change in Input-Output Coefficients: An Application to Acid Rain Policy." In Technological Forecasting and Social Change 33(1): pages 13-22.

Howell, David R. (1985). "The Future Employment Impacts of Industrial Robots: An InputOutput Approach." In Technological Forecasting and Social Change 28(4): pages 297-310.

INSEE (1995). “Les Tableaux des Entrées et Sorties.” in Paris, France, INSEE.

Lauritzen, F. C. (1982). “An Investigation of Danish Input-Output Tables, 1966-75." In Scandinavian Journal of Economics 84(3): pages 405-420.

Lee, Kwang-Soo (1982). "A Generalized Input-Output Model of an Economy with Environmental Protection." In The Review of Economics and Statistics 64: pages 466-473.

Leontief, Wassily (1936). "Quantitative Input-Output Relations in the Economic System of the United States." In The Review of Economics and Statistics 18(3): pages 105-125.

Lowe, Peter D. (1979). "Pricing Problems in an Input-Output Approach to Environmental Protection." In The Review of Economics and Statistics 61(1): pages 110-117.

Rhee, Jeong J. and John A. Miranowski (1984). "Determination of Income, Production, and Employment under Pollution Control: An Input-Output Approach." In The Review of Economics and Statistics 66(1): pages 146-150.

Venta, E. R. and A. M. Wolsky (1978). "Energy and Labor Cost for Gasoline Engine Remanufacturing." Argonne National Laboratory, Argonne, IL. (September 1978).

Wolsky, Alan M. (1984). "Disaggregating Input-Output Models." In The Review of Economics and Statistics 66(2): pages 283-291. 